\title{
Modelling of the in-plane behaviour of stone masonry panels
}

\author{
D.V. Oliveira, A.S. Araújo \& P.B. Lourenço \\ Department of Civil Engineering, ISISE, University of Minho, Guimarães, Portugal \\ G. Magenes \& A. Penna \\ University of Pavia, Pavia, Italy \\ European Centre for Training and Research in Earthquake Engineering, Pavia, Italy
}

\begin{abstract}
Stone masonry walls are the most relevant structural element in the seismic response of a masonry building. Once the out-of-plane mechanism are adequately prevented, the seismic response of a building depends on the in-plane strength capacity of its walls. This paper presents a discussion on the in-plane behaviour of masonry panels with different slenderness ratios and distinct levels of compression load, subjected to shear loading, using advanced numerical simulations. The numerical study is based on an experimental campaign performed at the University of Pavia on stone masonry piers. The calibrated models were also used to carry out parametric analysis varying the geometric wall configuration and the pre-compression level. Distinct walls subjected to different stress levels were assessed and the influence of these parameters on the in-plane behaviour is discussed.
\end{abstract}

\section{INTRODUCTION}

Walls represent the main resisting structural element in masonry buildings, ensuring resistance not only to vertical loading but also to wind or seismic actions. The in-plane behaviour of masonry walls is fully activated when an effective overall building response is accomplished by preventing brittle out-of-plane failure with appropriate connections.

When subjected to simultaneous in-plane compressive and shear loading, masonry walls experiment two typical types of behaviour that are associated to different failure modes: (i) rocking and toe crushing (flexural); (ii) sliding and diagonal cracking (shear) (Calderini et al. 2008; Moon 2004). However, some authors (Magenes and Calvi 1997; Tomaževič 1999; Parisi 2010;) identify a total of three failure modes, in which rocking and toe crushing are considered together and named as flexural failure. Rocking occurs when the wall begins to behave as a nearly rigid body rotating about the toe (Figure 1a). Toe crushing failure is usually associated with a compressive failure of masonry occurring at the toe of the pier (Figure 1b). The sliding failure is characterized by the wall deformation by sliding along a horizontal bed joint plane (Figure 1c) and in diagonal cracking the failure occurs due to the formation of diagonal cracks that usually develop in the centre of the wall and propagate towards the corners (Figure 1d). Walls fail according to the weakest failure mode and its occurrence depends essentially on the wall's geometry, boundary conditions and compression level.

This paper presents a discussion on the behaviour of masonry walls with different geometries and

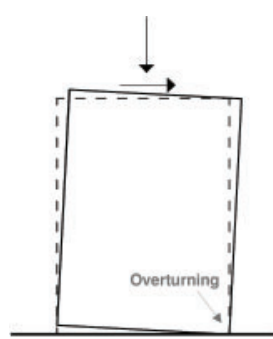

(a)

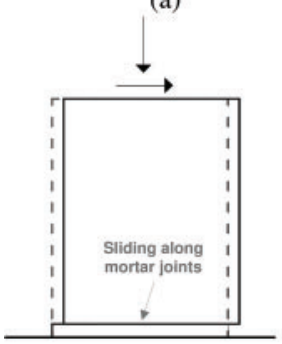

(c)

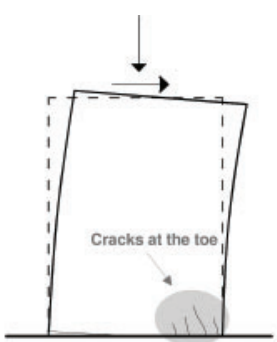

(b)

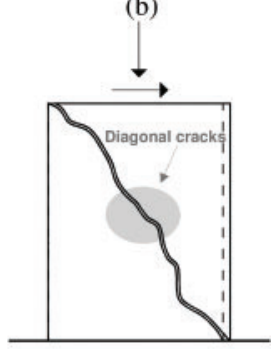

(d)
Figure 1. Typical failure mechanisms of masonry piers: (a) toe crushing; (b) rocking; (c) sliding; (d) diagonal cracking.

compression loading subjected to in-plane horizontal loads using advanced numerical simulations. The four walls under analysis were experimentally tested at University of Pavia, Italy. The experimental program included masonry piers with two slenderness ratios subjected to two distinct levels of axial load. 


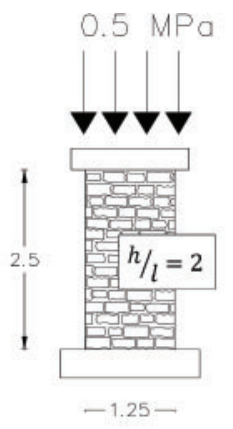

(a)

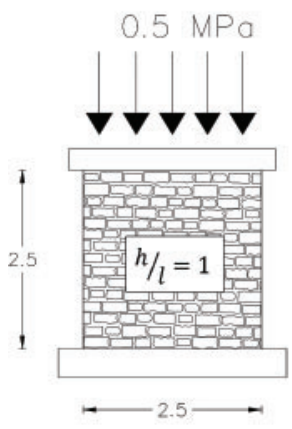

(c)

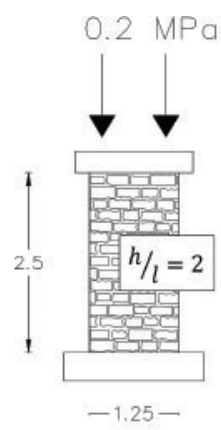

(b)

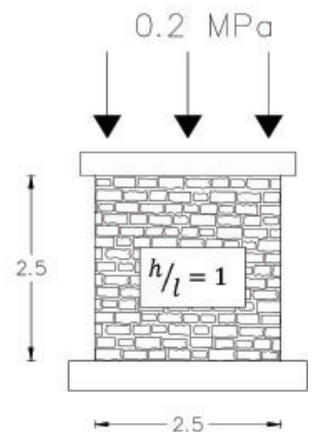

(d)
Figure 2. Wall specimens: (a) CS01; (b) CS02; (c) CT01; (d) $\mathrm{CT} 02$.

A parametrical analysis considering additional geometric configurations and compressive loads was also carried out.

\section{OUTLINE OF THE EXPERIMENTAL WORK}

The experimental research work was carried out at University of Pavia (Galasco et al. 2010; Magenes et al. 2010). The masonry typology is a double-leaf wall made of two vertical stone leaves. Information about materials, construction characteristics and mechanic properties of the masonry are reported elsewhere (Magenes et al. 2010; Araujo 2014).

In-plane cyclic shear tests were carried out aiming at reproducing the behaviour of masonry piers when subjected to in-plane reversed cyclic load, representative of the seismic action. These tests included the application of constant vertical forces and cyclic horizontal displacements applied at the top of the wall. Two geometric configurations were considered for two compression levels, of $0.2 \mathrm{MPa}$ and $0.5 \mathrm{MPa}$, respectively. All specimens have a height of $2.5 \mathrm{~m}$ and a thickness of $0.32 \mathrm{~m}$. Two of them have $1.25 \mathrm{~m}$ long (slender piers CS01 and CS02) and other two have $2.5 \mathrm{~m}$ long (squat piers CT01 and CT02), see Figure 2.

Specimens were built on a $40 \mathrm{~cm}$ thick reinforced concrete foundation fixed to the floor. The hydraulic actuators applied the axial load to the specimen through a steel loading beam connected to a reinforced concrete beam directly cast on top of the specimen. A third actuator was used to impose cyclic horizontal displacements to the top of the piers. The test setup imposed fixed restrain conditions to the piers at both the bottom and the top, providing a double bending configuration to specimens.

The maximum horizontal force reached by the specimens was: $94 \mathrm{kN}$ for CS01, $48 \mathrm{kN}$ for CS02, $234 \mathrm{kN}$ for CT01 and $154 \mathrm{kN}$ for CT02. Experiments revealed that piers CS01, CT01 and CT02 fail in shear by developing diagonal cracking. The slender specimen CS02 showed a combined flexural and shear failure.

The piers subjected to higher compressive loads proved to have more capacity in terms of horizontal load, when compared with the ones with the same geometry but lower level of compression. Specimens with lower levels of pre-compression exhibit more displacement capacity.

\section{NUMERICAL MODEL AND CALIBRATION}

\section{$3.1 \quad$ Numerical model adopted}

The finite element method was adopted for carrying out all numerical calculations (DIANA 9.4 2009). The experimental setup was numerically simulated, including the top concrete and metallic beams and the reinforced concrete foundation. The numerical models were constructed using 2D plane stress elements. A regular mesh discretization was developed using eight-node quadrilateral isoparametric plane stress elements.

Fixed-fixed conditions were assumed, namely pinned supports at the base while the rotation at the top metallic beam was prevented, as imposed by the experimental apparatus. The vertical compression was applied uniformly to the top of the steel beam and the horizontal load was considered as monotonic and was simulated by an explicit displacement.

A total strain rotating crack modeling was used for the nonlinear analysis, with a parabolic behaviour in compression and a softening behaviour in tension for masonry. Masonry is described as a continuous material and the parameters for the definition of the masonry behaviour were defined in accordance with experimental results, see Table 1 . Here, $E$ is the elastic modulus, $\gamma$ is the density, $f_{c}$ and $G_{c}$ are the compressive strength and fracture energy, $f_{t}$ and $G_{t}$ are the tensile strength and fracture energy, being the same for all walls. Typical values for the elastic modulus, poison coefficient and density were taken for the concrete and metallic beams and linear behaviour is assumed for these materials.

\subsection{Model calibration}

According to the constitutive model used, the numerical lateral elastic stiffness of walls depends on the 
Table 1. Mechanical properties for masonry.

\begin{tabular}{|c|c|c|c|c|c|}
\hline $\begin{array}{l}E \\
\left(\mathrm{~N} / \mathrm{mm}^{2}\right)\end{array}$ & $\begin{array}{l}\gamma \\
\left(\mathrm{N} / \mathrm{m}^{3}\right)\end{array}$ & $\begin{array}{l}f_{c} \\
\left(\mathrm{~N} / \mathrm{mm}^{2}\right)\end{array}$ & $\begin{array}{l}G_{c} \\
(\mathrm{~N} / \mathrm{mm})\end{array}$ & $\begin{array}{l}f_{t} \\
\left(\mathrm{~N} / \mathrm{mm}^{2}\right)\end{array}$ & $\begin{array}{l}G_{t} \\
(\mathrm{~N} / \mathrm{mm})\end{array}$ \\
\hline 2550 & 19000 & 3.28 & 5.25 & 0.14 & 0.02 \\
\hline
\end{tabular}

Table 2. Adopted elastic modulus for each wall.

\begin{tabular}{lllll}
\hline$E$ & & & & \\
$\left(\mathrm{~N} / \mathrm{mm}^{2}\right)$ & $\mathrm{CS} 01$ & $\mathrm{CS} 02$ & CT01 & CT02 \\
\hline & 1500 & 1100 & 1000 & 800 \\
\hline
\end{tabular}

masonry elastic modulus, the geometric configuration and the boundary conditions, but does not depend on the applied compression stress level. This implies that walls with the same geometric configuration $\mathrm{CS} 01 / \mathrm{CS} 02$ and $\mathrm{CT} 01 / \mathrm{CT} 02$ exhibit identical numerical lateral elastic stiffness. However, several experimental studies on the in-plane behaviour of masonry walls show that walls subjected to a greater pre-compression level tend to exhibit a higher initial stiffness (Magenes and Calvi 1992; Vasconcelos 2005; Elmenshawi et al. 2010; Capozucca 2011; Silva 2012; Petry and Beyer 2014).

Thus, the simulation of the experimentally tested walls requires the consideration of the precompression effect on the walls response. For that purpose, an "equivalent" elastic modulus was calibrated in order to adequate the numerical stiffness with the experimental one. Table 2 presents the adopted elastic modulus for each wall. Further details are provided in Araujo (2014).

\subsection{Results}

The numerical force-displacement curves are plotted for each wall and compared with the corresponding experimental envelopes, defined by plotting the envelope in each direction and combining them into one envelope.

The numerical response of the slender wall with higher pre-compression level, CS01, reveals a very good accordance with experiments in terms of initial stiffness, maximum lateral resistance and post-peak behaviour, see Figure 3a. The damage distribution presented in Figure $3 \mathrm{~b}$ indicates a shear failure, which is in agreement with the experimental failure mode. The response of the slender wall with lower compression stress, CS02, shows good agreement with the experimental envelope and predicts well the rocking failure mode, although the maximum in-plane capacity is slight overestimated, see Figure 4. The significant decrease of resistance observed in the experimental envelope could not be fully simulated. A possible explanation may raise on the non-consideration of the cyclic loading process. From the experimental point

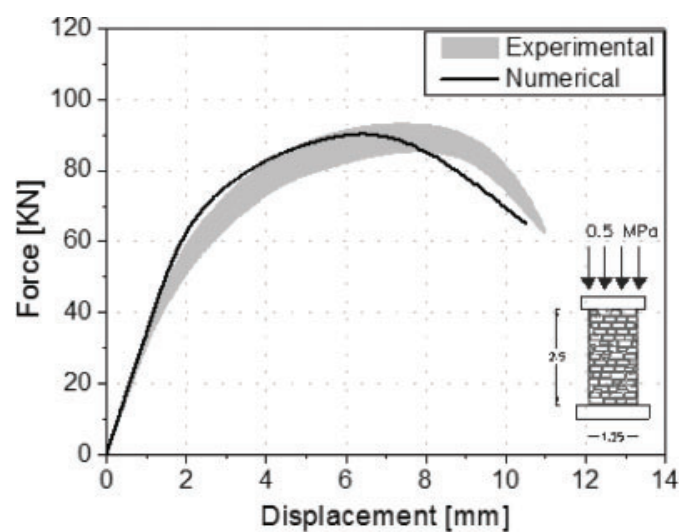

(a)

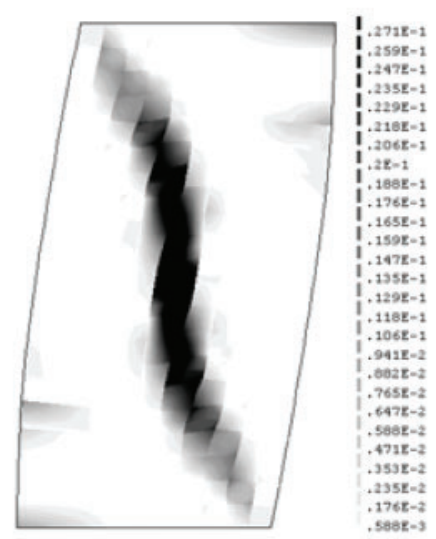

(b)

Figure 3. CS01 wall: (a) force-displacement curve; (b) maximum principal strains at post peak.

of view, the strength is dictated by flexural strength, but it is not far from the force needed to generate diagonal cracking. Since the experimental test is cyclic, a diagonal crack may have been possibly induced by the repetition of cycles that do not reach the monotonic diagonal cracking condition but stay close to it.

Figure 5a shows the in-plane behaviour of CT01 wall, which is in agreement with experiments as the maximum capacity is well estimated and the non-linear behaviour follows the experimental curve. The discontinuity visible in the capacity curve of this wall can be explained by the opening of the first numerical crack followed by the subsequent stresses redistribution. The numerical results obtained for the squat wall with lower compression level, CT02, proved that the experimental in-plane behaviour is also numerically well reproduced, see Figure 6a. Also, the shear failure described in the experiments was observed numerically with the formation of diagonal cracks between the top corner and the wall toe (Figure $5 \mathrm{~b}$ and Figure 6b). A higher pre-compression load leads to greater inplane capacity, as verified experimentally, and minor level of damage. 


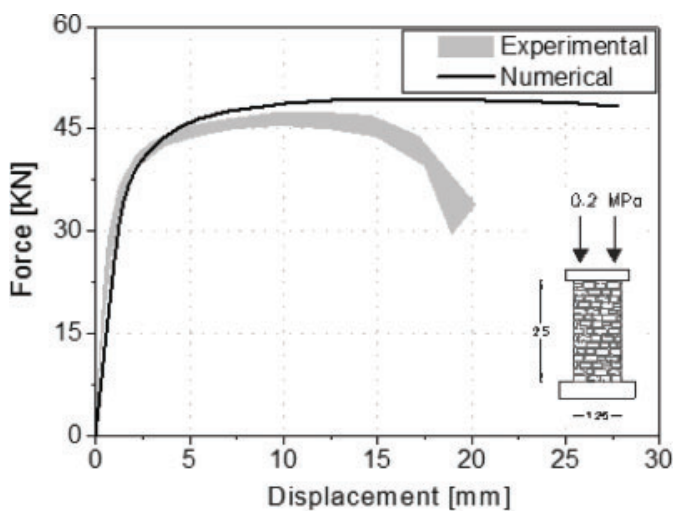

(a)

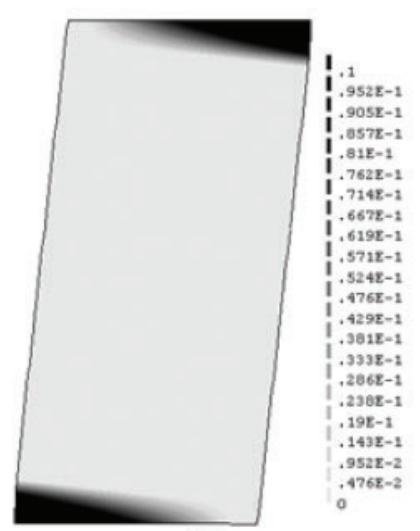

(b)

Figure 4. CS02 wall: (a) force-displacement curve; (b) maximum principal strains at the post peak.

Based on the comparison between numerical and experimental results (capacity curves and damage patterns), it can be concluded that the numerical model is able to reproduce the experimental in-plane behaviour of the four masonry walls, namely the initial stiffness, the load capacity and failure modes.

\section{PARAMETRIC ANALYSIS}

This section aims at exploiting the model and to further clarify the interaction between the pre-compression level and the wall slenderness ratio $(h / l)$ in the inplane response of the masonry walls under shear loading. For this purpose, parametrical analysis considering an intermediate geometric relation $(h / l)$ and a pre-compression level were carried out though interpolation, see Table 3 . Walls with $2.5 \mathrm{~m}$ high and $1.875 \mathrm{~m}$ long, comprising an $h / l$ ratio of around 1.33 (named as CM walls), were included in the numerical analysis and a pre-compression level of $0.35 \mathrm{MPa}$ was also studied. In total, the in-plane response of nine masonry panels is numerically estimated.

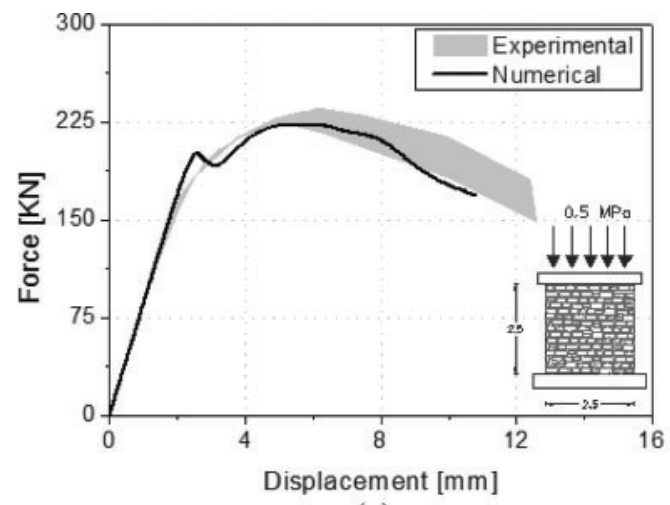

(a)

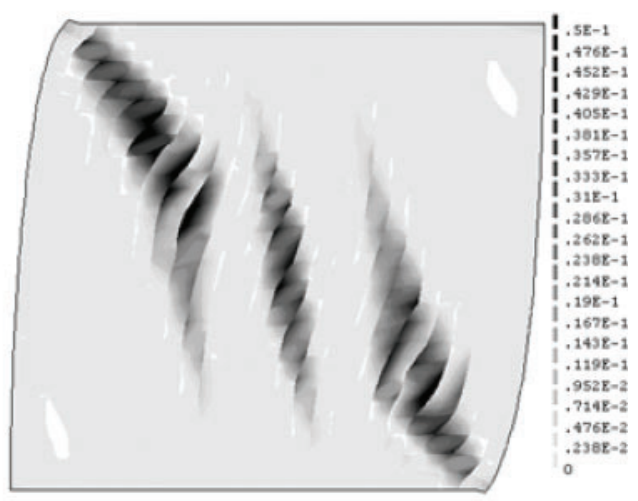

(b)

Figure 5. CT01 wall: (a) force-displacement curve (b) maximum principal strains at post peak.

The parametric analyses were performed based on the same assumptions made for the validated models. The analysis results were grouped considering the precompression level and the geometric configuration in order to evaluate the influence of these parameters on the response of the wall, see Figure 7 and Figure 8.

Figure 7 describes the influence of the geometrical configuration in the wall behaviour, where it is observed that larger height/length ratios led to lower capacity of the wall, independently of the level of compression stress. When the vertical compression was kept constant and the walls geometry varied, an average increase in the lateral wall capacity of around $90 \%$ was verified comparing walls of $h / l$ ratio equal to 2 with $h / l$ equal to 1.33 . A moderate enhancement of the walls strength capacity near $30 \%$ was verified for walls of $h / l$ ratio equal to 2 when compared to the ratio 1.33 . These growths are not so pronounced for the $0.35 \mathrm{MPa}$ pre-compression level.

The contribution of the pre-compression level on the wall behaviour is assessed by in Figure 8, where the influence of the stress level is evaluated for a same geometric configuration. It is clear that the lateral strength is enhanced by increasing the level of pre-compression on the wall, for all geometric configurations. The 


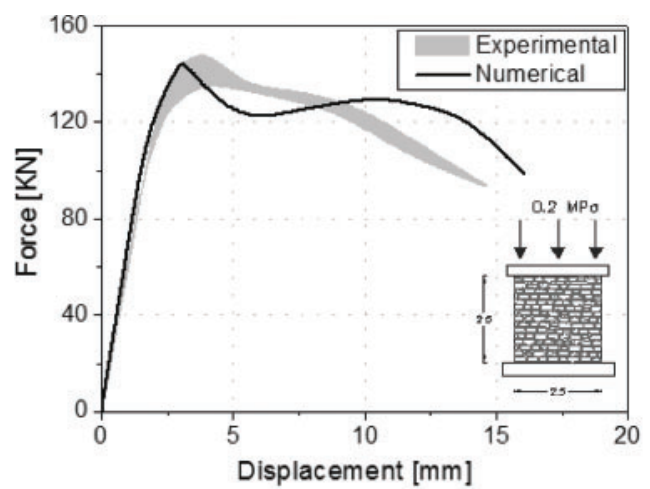

(a)

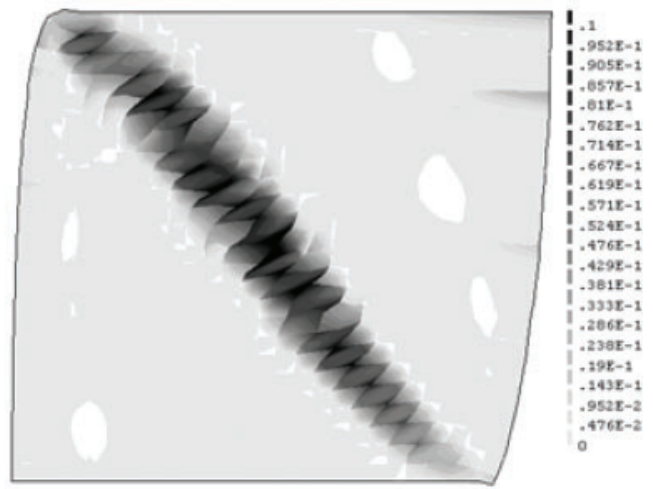

(b)

Figure 6. CT02 wall: (a) force-displacement curve (b) maximum principal strains at post peak.

Table 3. Parametrical analysis (walls tested experimentally are in in light grey).

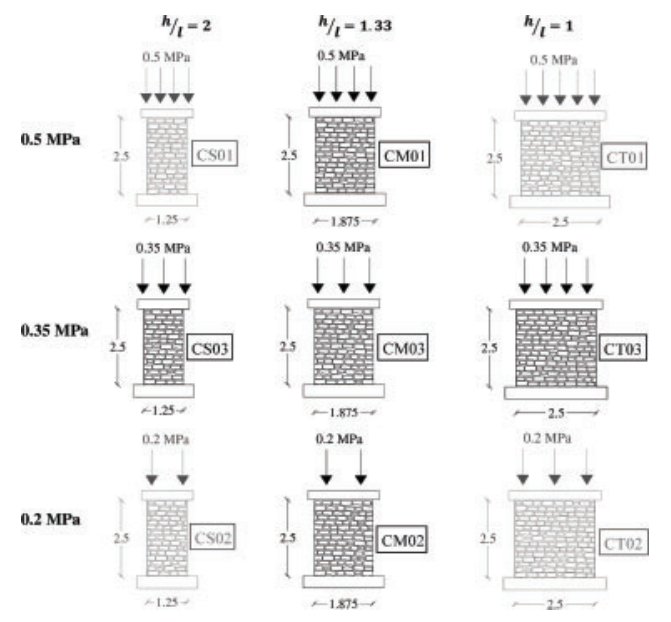

non-linear behaviour response of the walls is also influenced by the level of pre-compression. Walls with lower compression levels and greater height/length relations (slender configurations) tend to exhibit a

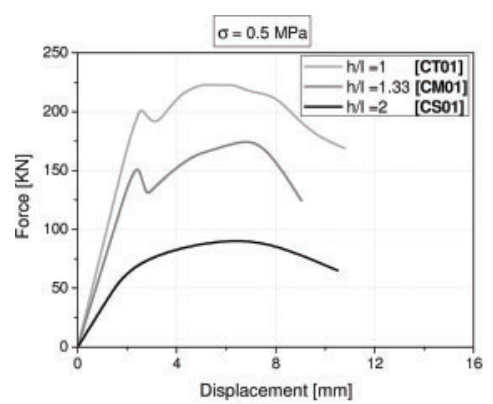

(a)

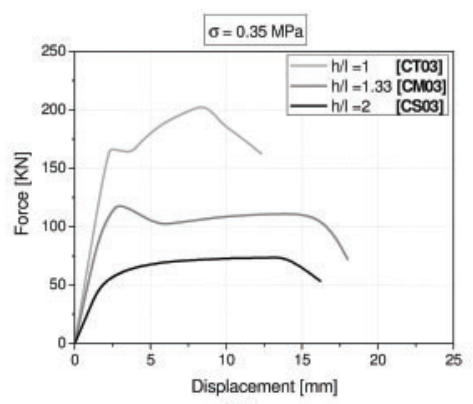

(b)

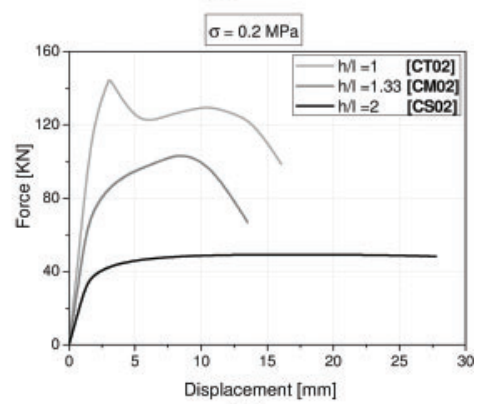

(c)

Figure 7. Force-displacement curves of the parametric analyses: comparison according the compression level: (a) $0.5 \mathrm{MPa}$; (b) $0.35 \mathrm{MPa}$; (c) $0.2 \mathrm{MPa}$.

smooth evolution of the force-displacement curve, typical of flexural behaviour. In what concerns the maximum capacity, the results are very consistent and close to the ones given by other experimental tests results. It is observed that the vertical stress level influences also the failure mode developed in the pier.

Figure 9 shows the maximum principal strains distribution of the walls from the parametric analysis in which the transition from flexural behaviour to shear behaviour is clear. From the results it is possible to observe that the wall with slender configuration subjected to a compression of $0.35 \mathrm{MPa}$ (CS03 wall) suffers a combined shear flexure failure. Similarly, the wall with mean slenderness ratio subjected to low compression (0.2 MPa), CM02 wall, present a damage pattern typical of flexural behaviour including overturning of the wall and shear diagonal cracking in the centre of the wall. Although the evident flexure 


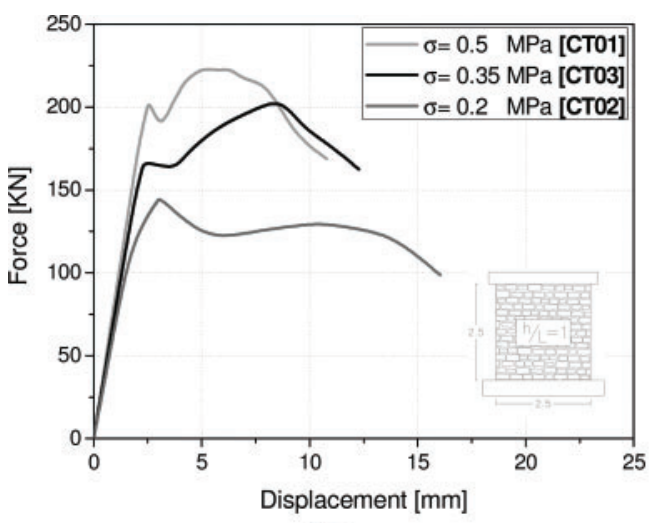

(a)

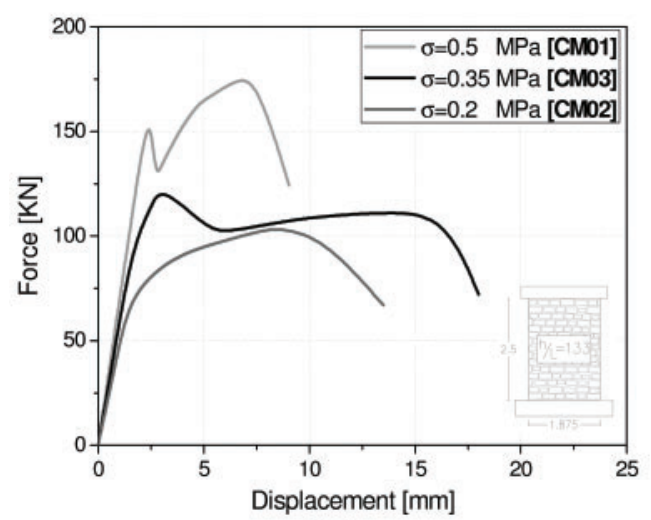

(b)

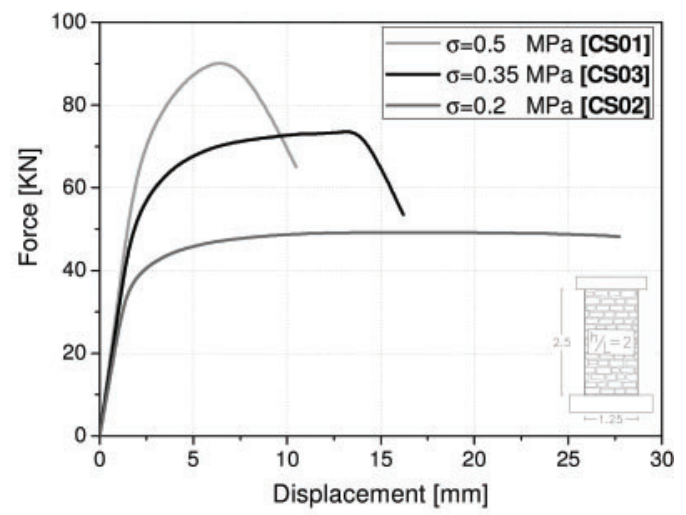

(c)

Figure 8. Force-displacement curves of the parametric analyses: comparison according the geometric configuration: (a) $h / l=1$; (b) $h / l=1.33$; (c) $h / l=2$.

response experimented by this wall, the failure occurs due to the diagonal cracking.

The walls with lower slenderness ratio configurations combined with high levels of pre-compression, besides achieving a higher in-plane capacity, are governed by shear behaviour. The crack patterned verified

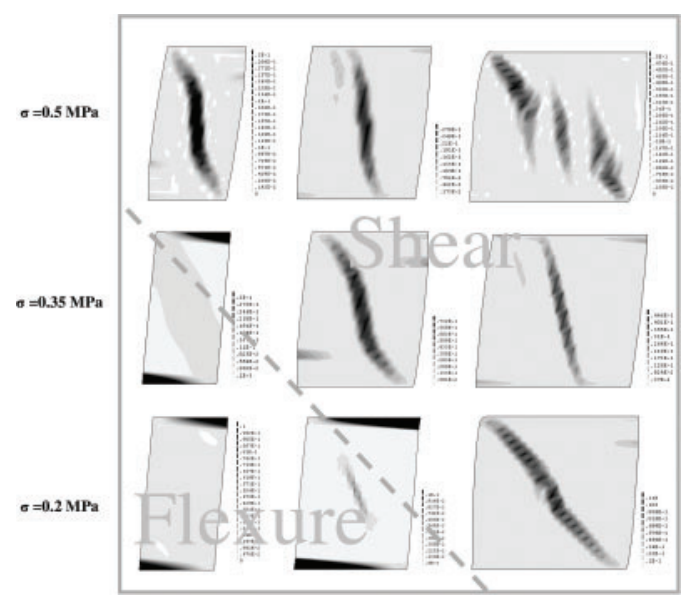

Figure 9. Maximum principal strain distribution for the parametrical analysis.

for the remaining walls was the development of diagonal cracks at the centre of the pier, as shown in Figure 9.

\section{FINAL CONSIDERATIONS}

The understanding of the behaviour of masonry walls under in-plane loading can be significantly improved by numerical approaches, when properly applied. The validation of the numerical models is a key issue to gain confidence for the subsequent steps.

The in-plane behaviour of masonry walls tested experimentally was done resorting to finite element models. In order to calibrate the numerical models, the elastic modulus of masonry was updated for adjustment of the walls' stiffness to the experimental behaviour.

Good agreement was found between the experimental force-displacement envelopes and the numerical capacity curves. The observed failure modes of the masonry walls were also well estimated numerically.

The study of masonry walls was extended to other configurations and stress levels by taking advantage of the validated numerical models. The results allowed for the in-plane behaviour characterization of 5 more walls. It was possible to confirm that flexure failure was predominant in slender walls with low levels of pre-compression.

\section{ACKNOWLEDGMENT}

The second author would like to express her gratitude to the National Foundation for Science and Technology (FCT) for the PhD grant SFRH/BD/71599/2010. This work was supported by FCT, within ISISE, project UID/ECI/04029/2013. 


\section{REFERENCES}

Araujo, A. 2014. Modelling of the seismic performance of connections and walls in ancient masonry buildings. $\mathrm{PhD}$ Thesis, University of Minho.

Calderini, C., Cattari, S., and Lagomarsino, S. 2008. Inplane strength of unreinforced masonry piers. Earthquake Engineering \& Structural Dynamics.

Capozucca, R. 2011. Shear behaviour of historic masonry made of clay bricks. The Open Construction and Building Technology Journal 5(1): 89-96.

Elmenshawi, A., Sorour, M., Mufti, A., Jaeger, L.G., Shrive, N. 2010. In-plane seismic behaviour of historic stone masonry. Canadian Journal of Civil Engineering.

Galasco, A., Magenes, G., Penna, A., Da Paré, M. 2010. Inplane cyclic shear tests of undressed double leaf stone masonry panels. 14th European Conference in Earthquake Engineering.

Magenes, G., Calvi, G. M. 1992. Cyclic behaviour of brick masonry walls. 10th World Conference in Earthquake Engineering. Rotterdam, 3517-3522.

Magenes, G., Calvi, G.M. 1997. In-plane seismic response of brick masonry walls. Earthquake Engineering \& Structural Dynamics 26(11): 1091-1112.
Magenes, G., Penna, A., Galasco, A., Rota, M. 2010. Experimental characterisation of stone masonry mechanical properties. 8th International Masonry Conference, Dresden, $1-10$.

Moon, F.L. 2004. Seismic strengthening of low-rise unreinforced masonry structures with flexible diaphragms. $\mathrm{PhD}$ Thesis, Georgia Institute of Technology.

Parisi, F. 2010. Non-linear seismic analysis of masonry buildings. PhD Thesis, University of Naples Federico II.

Petry, S., Beyer, K. 2014. Influence of boundary conditions and size effect on the drift capacity of URM walls. Engineering Structures 65: 76-88.

Silva, B. 2012. Diagnosis and strengthening of historical masonry structures: numerical and experimental analysis. $\mathrm{PhD}$ Thesis, University of Brescia.

TNO DIANA 2009. DIANA. DIsplacement method ANAlyser, release 9.4, User's Manual.

Tomaževič, M. 1999. Earthquake-resistant design of masonry buildings. Imperial College Press.

Vasconcelos, G. 2005. Experimental investigations on the mechanics of stone masonry: Characterization of granites and behavior of ancient masonry shear walls. $\mathrm{PhD}$ Thesis, University of Minho. 